\title{
Genetic Risk for Hemochromatosis is Associated with Movement
} Disorders

Robert Loughnan ${ }^{1,2}$, Jonathan Ahern ${ }^{1}$, Cherisse Thompkins ${ }^{1}$, Clare E. Palmer ${ }^{3}$, Leo Sugrue ${ }^{4}$, John Iversen ${ }^{3}$, Wesley Thompson ${ }^{2,5}$, Ole Andreassen ${ }^{6}$, Terry Jernigan ${ }^{1,3,7,8}$, Anders Dale ${ }^{1,6,9,10}$, Mary ET Boyle ${ }^{* 1,11}$, Chun Chieh Fan ${ }^{* 2,10}$

1. Department of Cognitive Science, University of California, San Diego, 9500 Gilman Drive, La Jolla, CA 92093, USA

2. Population Neuroscience and Genetics, University of California, San Diego, 9500 Gilman Drive, La Jolla, CA 92161, USA

3. Center for Human Development, University of California, San Diego, 9500 Gilman Drive, La Jolla, CA 92161, USA

4. Department of Radiology and Biomedical Imaging, University of California, San Francisco, 505 Parnassus Avenue, San Francisco, CA 94143, USA

5. Herbert Wertheim School of Public Health, University of California, San Diego, La Jolla, CA, USA

6. NORMENT Centre, Division of Mental Health and Addiction, Oslo University Hospital \& Institute of Clinical Medicine, University of Oslo, Oslo, Norway

7. Department of Radiology, University of California, San Diego School of Medicine, 9500 Gilman Drive, La Jolla, CA 92037, USA

8. Department of Psychiatry, University of California, San Diego School of Medicine, 9500 Gilman Drive, La Jolla, CA 92037, USA

9. Department of Neuroscience, University of California, San Diego School of Medicine, 9500 Gilman Drive, La Jolla, CA 92037, USA

10. Center for Multimodal Imaging and Genetics, University of California, San Diego School of Medicine, 9444 Medical Center Dr, La Jolla, CA 92037, USA

11. Johns Hopkins Bloomberg School of Public Health, 615 N. Wolfe Street, Baltimore, MD 21205, USA

*These authors contributed equally.

Word Count: 2,747 
medRxiv preprint doi: https://doi.org/10.1101/2021.08.16.21262117; this version posted August 24, 2021. The copyright holder for this preprint (which was not certified by peer review) is the author/funder, who has granted medRxiv a license to display the preprint in perpetuity.

It is made available under a CC-BY-NC 4.0 International license .

\section{Abstract}

Hereditary hemochromatosis $(\mathrm{HH})$ is an autosomal recessive genetic disorder that can lead to iron overload, causing oxidative damage to affected organs. HH type 1 is predominantly associated with homozygosity for the mutation p.C282Y. Previous case studies have reported tentative links between $\mathrm{HH}$ and movement disorders, e.g., Parkinson's disease, and basal ganglia abnormalities on magnetic resonance imaging. We investigated the impact of p.C282Y homozygosity: on whole brain $\mathrm{T} 2$ intensity differences, a measure of iron deposition, and; on measures of movement abnormalities and disorders within UK Biobank. The neuroimaging analysis (154 p.C282Y homozygotes, 595 matched controls) showed that p.C282Y homozygosity was associated with decreased T2 signal intensity in motor circuits (basal ganglia, thalamus, red nucleus, and cerebellum; Cohen's d > 1) consistent with substantial iron deposition. Across the whole UK Biobank (2,889 p.C282Y homozygotes, 496,968 controls), we found a significant enrichment for movement abnormalities in male homozygotes (OR (95\% CI) $=1.82(1.27-2.61), \mathrm{p}=0.001)$, but not females $(\mathrm{OR}(95 \% \mathrm{CI})=1.10(0.69-1.78), \mathrm{p}=0.71)$. Among the 31 p.C282Y homozygote males with a movement disorder only 7 had a concurrent $\mathrm{HH}$ diagnosis. These findings indicate susceptibility to iron overload in subcortical structures in p.C282Y homozygotes, and confirmed an increased risk of movement abnormalities and disorders in males. Given the effectiveness of early treatment in HH, screening for p.C282Y homozygosity in high risk individuals may offer a potential avenue to reduce iron accumulation in the brain and limit additional risk for the development of movement disorders among males. 


\section{Introduction}

Hereditary hemochromatosis $(\mathrm{HH})$ is a disorder that leads to iron overload in the body.

$\mathrm{HH}$ type 1 is predominantly related to a HFE gene mutation, with $95 \%$ of cases being homozygote for p.C282Y (p.Cyst282Tyr) mutation ${ }^{1}$. The excess iron absorbed by the body leads to an accumulation of iron in organs, particularly in the liver leading to increased risk for liver disease and diabetes ${ }^{2}$. With a homozygosity rate of approximately $0.6 \%$ in northern European populations, it has been deemed the most prevalent genetic disorder in Europe $\mathrm{e}^{3,4}$. The penetrance of $\mathrm{HH}$ and other associated diseases in p.C282Y homozygote individuals appears to be larger for males than females ${ }^{5}$, leading researchers to believe that expelling excess iron through menstruation and pregnancy lowers disease burden and penetrance in females. The primary treatment for $\mathrm{HH}$ is phlebotomy which appears to be effective at reducing adverse clinical outcomes $^{3}$ if started early. As a result, some researchers have advocated for re-evaluating screening and early case ascertainment ${ }^{2}$.

Although the impact of $\mathrm{HH}$ and p.C282Y homozygosity on the liver and heart is largely accepted $^{2,3}$, its effect on the central nervous system is still disputed. While some studies have reported a higher risk for Alzheimer's and Parkinson's disease in p.C282Y homozygote individuals ${ }^{5,6}$, other studies have reported no risk $^{7,8}$ or a protective effect ${ }^{9}$. These conflicting results may be explained by modest sample sizes and pooled analysis across sexes. Case studies of $\mathrm{HH}$ individuals experiencing neurological deficits have confirmed neuroimaging abnormalities in the basal ganglia, substantia nigra, and cerebellum ${ }^{10,11,12}$, all regions known to have a substantial role in the control of movement ${ }^{13}$. However, these previous studies included only individuals diagnosed with $\mathrm{HH}$, and therefore do not describe neurological deficits and abnormalities of p.C282Y homozygote individuals independent of HH diagnosis. A recent study 
medRxiv preprint doi: https://doi.org/10.1101/2021.08.16.21262117; this version posted August 24, 2021. The copyright holder for this preprint (which was not certified by peer review) is the author/funder, who has granted medRxiv a license to display the preprint in perpetuity.

It is made available under a CC-BY-NC 4.0 International license .

performed an analysis of brain MRI data from 206 p.C282Y homozygote individuals taken from the UK Biobank ${ }^{14}$. Using analyses of $\mathrm{T} 2^{*}$ signal in predefined anatomical regions (Region Of Interest-based) they found indications of increased iron deposition in subcortical structures and cerebellum for p.C282Y homozygote individuals, and increased risk of dementia in p.C282Y homozygote males.

Since the implicated brain regions with p.C282Y homozygosity are known to have a strong involvement in motor functions ${ }^{15}$ and reports of movement deficits in $\mathrm{HH}$ individuals $^{5,6,10,11}$, we investigated the relationship between p.C282Y homozygosity and movement disorders in 502,536 individuals from the UK Biobank, with improved imaging technology enabling greater granularity of associations across the brain. Specifically, we investigated: i) the impact of p.C282Y homozygosity on whole brain voxel-wise measures of iron deposits; ii) the sex stratified association of p.C282Y homozygosity with movement disorders and tested for overlap with $\mathrm{HH}$ diagnosis.

\section{Methods}

\section{UK Biobank Sample}

Genotypes, MRI scans, demographic and clinical data were obtained from the UK

Biobank under accession number 27412, excluding participants who withdrew their consent.

This resulted in a total sample of 502,536 individuals with a mean age of 57.0 years (standard deviation 8.1 years), 229,134 male. We used UK Biobank v3 imputed genotype data ${ }^{30}$. From this sample, 2,889 individuals were identified as homozygote for p.C282Y (A/A at rs1800562), 1,293 male. As previous research does not indicate intermediate disease burden for p.C282Y heterozygotes $^{2}$, we coded control individuals as homozygote for no risk allele (G/G at rs 1800562) or heterozygote (A/G at rs1800562) i.e., with a recessive model of inheritance. This resulted in 499,647 controls, 227,841 male. 


\section{Neuroimaging Analysis}

Image acquisition

T1 weighted and diffusion weighted scans were collected from three scanning sites throughout the United Kingdom, all on identically configured Siemens Skyra 3T scanners, with 32-channel receiver head coils. For diffusion scans, multiple scans with no diffusion gradient were collected $\left(b=0 \mathrm{~s} / \mathrm{mm}^{2}\right)$ to fit diffusion models. The average of these $b=0$ scans was used as voxel-wise measures of T2 intensities. Diffusion weighted scans were collected using an SE-EPI sequence at $2 \mathrm{~mm}$ isotropic resolution. T1 scans were collected using a 3D MPRAGE sequence at $1 \mathrm{~mm}$ isotropic resolution.

Image Preprocessing

Scans were corrected for nonlinear transformations provided by MRI scanner manufacturers $^{31,32}$, and T2 images were registered to T1 weighted images using mutual information $^{33}$. Intensity inhomogeneity correction was performed by applying smoothly varying, estimated B1-bias field ${ }^{34}$. Images were rigidly registered and resampled into alignment with a pre-existing, in-house, averaged, reference brain with $1.0 \mathrm{~mm}$ isotropic resolution ${ }^{34}$.

\section{Atlas Registration}

To allow for voxel-wise analysis, subjects' imaging data were aligned using a multimodal nonlinear elastic registration algorithm. At the end of the preprocessing steps outlined in Image Processing and described in detail in Hagler et al. ${ }^{34}$, subjects' structural images and diffusion parameter maps were aligned to an UK Biobank-specific atlas, using a custom diffeomorphic registration method.

\section{Labelling regions of interest $(\mathrm{ROI})$}

Subcortical structures were labeled using Freesurfer 5.3 ${ }^{35}$. Subjects' native space Freesurfer parcellations were warped to the atlas space and averaged across subjects. Additional subcortical nuclei, not available in the FreeSurfer segmentation, were labeled by 
medRxiv preprint doi: https://doi.org/10.1101/2021.08.16.21262117; this version posted August 24, 2021. The copyright holder for this preprint (which was not certified by peer review) is the author/funder, who has granted medRxiv a license to display the preprint in perpetuity.

It is made available under a CC-BY-NC 4.0 International license .

registering readily available, downloadable, high spatial resolution atlases to our atlas space. The Pauli atlas was generated using T1 and T2 scans from 168 typical adults from the Human Connectome Project $(\mathrm{HCP})^{36}$. The Najdenovska thalamic nuclei atlas was generated using a kmeans algorithm taking as inputs mean fibre orientation density spherical harmonic coefficients from within a Freesurfer parcellation of the thalamus, using adult HCP data from 70 subjects $^{37}$. All subcortical ROIs and abbreviations are listed in Supplementary Table 2.

\section{Covariate Matched Controls}

From the full 2,889 p.C282Y homozygotes, only 154 had qualified imaging. As we did not want to have a large imbalance between the number of controls and p.C282Y homozygotes, we selected covariate matched controls at a ratio of 4:1 (controls:cases). We matched controls on age, sex, scanner, mean cortical area, and top ten components of genetics ancestry. These matched controls were generated through using the sample of 154 individuals with qualified imaging, fitting a logistic model to predict p.C282Y homozygosity from the listed covariates, and then generating propensity scores ${ }^{38}$ for each individual. Controls were selected on having propensity scores with a threshold of $\left|s_{1}-s_{2}\right| \leq$ threshold, where $s_{1}$ and $s_{2}$ were the respective propensity scores of a p.C282Y homozygote and their matched control. The threshold was set to $1.5 \times 10^{-4}$. We performed this procedure by using the pymatch library (version 0.3 .1 ) in python $^{39}$. This resulted in 154 p.C282Y homozygotes (64 male) and 595 controls (248 male).

\section{Statistical analysis}

General linear effect models were applied univariately to test the association between p.C282Y homozygosity and T2 intensities. Each voxel-wise T2 intensity was pre-residualized for age, sex, scanner, and top ten principal components of genetic ancestry. We then calculated Cohen's d effect sizes as the residualized voxel-wise differences between p.C282Y homozygotes and controls. As previous research has indicated a higher disease burden for p.C282Y 
medRxiv preprint doi: https://doi.org/10.1101/2021.08.16.21262117; this version posted August 24, 2021. The copyright holder for this preprint (which was not certified by peer review) is the author/funder, who has granted medRxiv a license to display the preprint in perpetuity.

It is made available under a CC-BY-NC 4.0 International license .

homozygote males vs females, we in supplementary results we additionally performed a sexstratified analysis in 312 males (64 p.C282Y homozygote) and 437 females (90 p.C282Y homozygote).

\section{Neurological Disease Burden Analysis}

Given our neuroimaging findings of substantially lower T2 intensities of p.C282Y homozygotes in motor and gait circuits of the brain - indicative of iron deposition - we wanted to test if p.C282Y homozygosity imparted any risk for i) movement disorders, ii) gait disorders and iii) a broad category of neurological disorders. As completing imaging was not an inclusion criterion for this portion of the analysis, we included the entire sample listed above. We did not perform any covariate-matching of controls. Sex stratified logistic models fit 229,134 males (1,293 p.C282Y homozygote) and 273,402 females (p.C282Y 1,596 homozygote) to predict diagnosis from p.C282Y homozygosity status controlling for age, sex, and top ten principal components of genetic ancestry. We fit three models for each sex to test the domains described above, predicting: movement disorders [ICD10: G20-G26], abnormalities of gait and mobility [ICD10: R26], and other disorders of the nervous system [ICD10: G90-99]. We fit an additional three models, two to for the largest diagnoses of movement disorders; Parkinson's disease [ICD10: G20] and essential tremor [ICD10: G25], as well as a super-category of significantly associated diagnoses combining a diagnosis of either a) movement disorders or b) other disorders of the nervous system into a single outcome. 


\section{Results}

\begin{tabular}{|c|c|c|}
\hline & Neuroimaging Analysis & Neurological Disease Analysis \\
\hline Sample Size & 749 (312 males) & $502,563$ (229,134 males $)$ \\
\hline p.C282Y Homozygotes & 154 (64 males) & 2,889 (1,293 males) \\
\hline
\end{tabular}

Table 1 Sample size for each analysis.

\section{Neuroimaging Analysis}

We performed a voxel-wise analysis of T2 intensities (lower T2 intensity consistent with higher iron deposition ${ }^{17}$ ) of using p.C282Y homozygosity status as our predictor of interest - see Table 1 for sample sizes. We found evidence for iron deposition reflected in substantially lower T2 intensities localized to the basal ganglia, thalamus and cerebellum in p.C282Y homozygote individuals. p.C282Y homozygosity was associated with lower T2 intensities in bilateral caudate nucleus, putamen, thalamus (specifically the ventral anterior, ventral lateral dorsal, ventral-lateral ventral and pulvinar nuclei), red nucleus, sub-thalamic nucleus, and both white and grey matter of the cerebellum (Figure 1). Additionally, we observed higher T2 intensities in the white matter of the superior cerebellar peduncle, possibly indicating gliosis in this region ${ }^{18}$ which comprises the primary output pathway from the cerebellum to the thalamus and red nucleus. Supplementary sex-stratified analysis revealed similar effects in males and females, with p.C282Y homozygote females having on average approximately $30 \%$ smaller effects than males (supplementary figures 1-2). 
medRxiv preprint doi: https://doi.org/10.1101/2021.08.16.21262117; this version posted August 24, 2021. The copyright holder for this preprint (which was not certified by peer review) is the author/funder, who has granted medRxiv a license to display the preprint in perpetuity.

It is made available under a CC-BY-NC 4.0 International license .

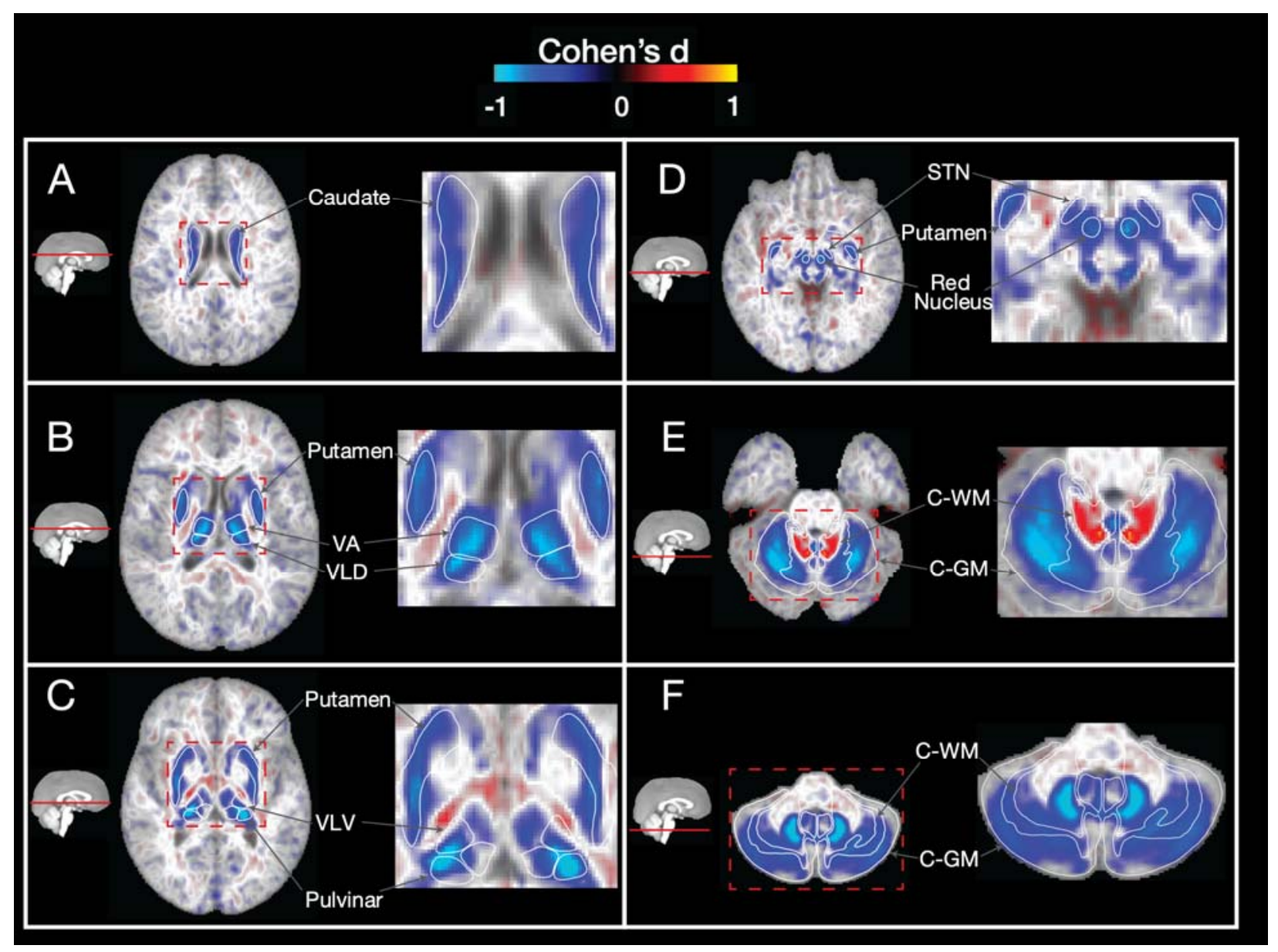

Figure 1 Voxelwise associations (cohen's d) of T2 intensities between matched controls vs p.C282Y homozygote individuals. Blue regions represent lower T2 intensities (indicating higher iron deposition) for p.C282Y homozygotes. Lower T2 intensities are observed for p.C282Y homozygotes in the A. caudate nucleus, B. putamen, ventral anterior and ventral lateral dorsal nuclei of the thalamus, C. ventral-lateral ventral and pulvinar nuclei of the thalamus, D. red nucleus, sub thalamic nucleus, E. and F. grey and white matter of the cerebellum. Higher T2 intensities are observed in E. in the superior cerebellar peduncle (primary output pathway connecting the cerebellum to the thalamus and red nucleus).

\section{Neurological Disease Burden Analysis}

The brain regions identified in our analysis have previously been implicated to have a strong involvement in motor control ${ }^{15,19}$. We aimed to determine if p.C282Y homozygote 
medRxiv preprint doi: https://doi.org/10.1101/2021.08.16.21262117; this version posted August 24, 2021. The copyright holder for this preprint (which was not certified by peer review) is the author/funder, who has granted medRxiv a license to display the preprint in perpetuity.

It is made available under a CC-BY-NC 4.0 International license .

individuals had an enrichment for movement abnormalities, including movement diseases and gait/mobility, or other disorders of the nervous system. Table 1 displays the sample size for this analysis. As males appear to have a greater penetrance for $\mathrm{HH}$ and other associated diseases ${ }^{2}$, we performed a sex-stratified analysis. We found that p.C282Y homozygote males had a higher chance of being diagnosed with a movement disorder $(\mathrm{OR}(95 \% \mathrm{CI})=1.82(1.27-2.61)$, $\mathrm{p}=0.001)$ and other disorders of the nervous system $(\mathrm{OR}(95 \% \mathrm{CI})=1.51(1.06-2.14), \mathrm{p}=0.02)$. The International Classifications for Diseases (ICD) chapter of movement disorders includes Parkinson's disease and essential tremor, which were both associated with p.C282Y homozygosity in males (Parkinson's disease: OR $(95 \% \mathrm{CI})=1.78(1.14-2.79), \mathrm{p}=0.01$ and essential tremor: OR $(95 \% \mathrm{CI})=1.92(1.03-3.60), \mathrm{p}=0.04) \cdot \mathrm{p} . \mathrm{C} 282 \mathrm{Y}$ homozygote males did not have a higher chance of being diagnosed with gait or mobility disorders $(\mathrm{OR}(95 \% \mathrm{CI})=0.96$ (0.65-1.42), $\mathrm{p}=0.85)$. No significant associations were found for $\mathrm{p} . \mathrm{C} 282 \mathrm{Y}$ homozygote females for any diagnosis tested - see Figure 2 panel A and Supplementary Table 2.

Given the convergence of our neuroimaging and genetic associations on movement related circuits of the brain and movement disorders, p.C282Y homozygosity may lead to brain pathology that is undetected in sub-clinical $\mathrm{HH}$ cases. As the treatment of care for disorders like Parkinson's differs from that of hemochromatosis ${ }^{3,20}$, we looked at the overlap of individuals with neurological diagnoses and a clinical diagnosis of hemochromatosis for p.C282Y homozygote males. We found that for p.C282Y homozygote males with a movement disorder diagnosis (31 individuals), most (24 individuals) did not have a concurrent $\mathrm{HH}$ diagnosis. We also found a similar pattern for other nervous system disorders where 10 out of 33 men had a concurrent hemochromatosis diagnosis - see Figure 2 panel B. 
medRxiv preprint doi: https://doi.org/10.1101/2021.08.16.21262117; this version posted August 24, 2021. The copyright holder for this preprint (which was not certified by peer review) is the author/funder, who has granted medRxiv a license to display the preprint in perpetuity.

It is made available under a CC-BY-NC 4.0 International license .
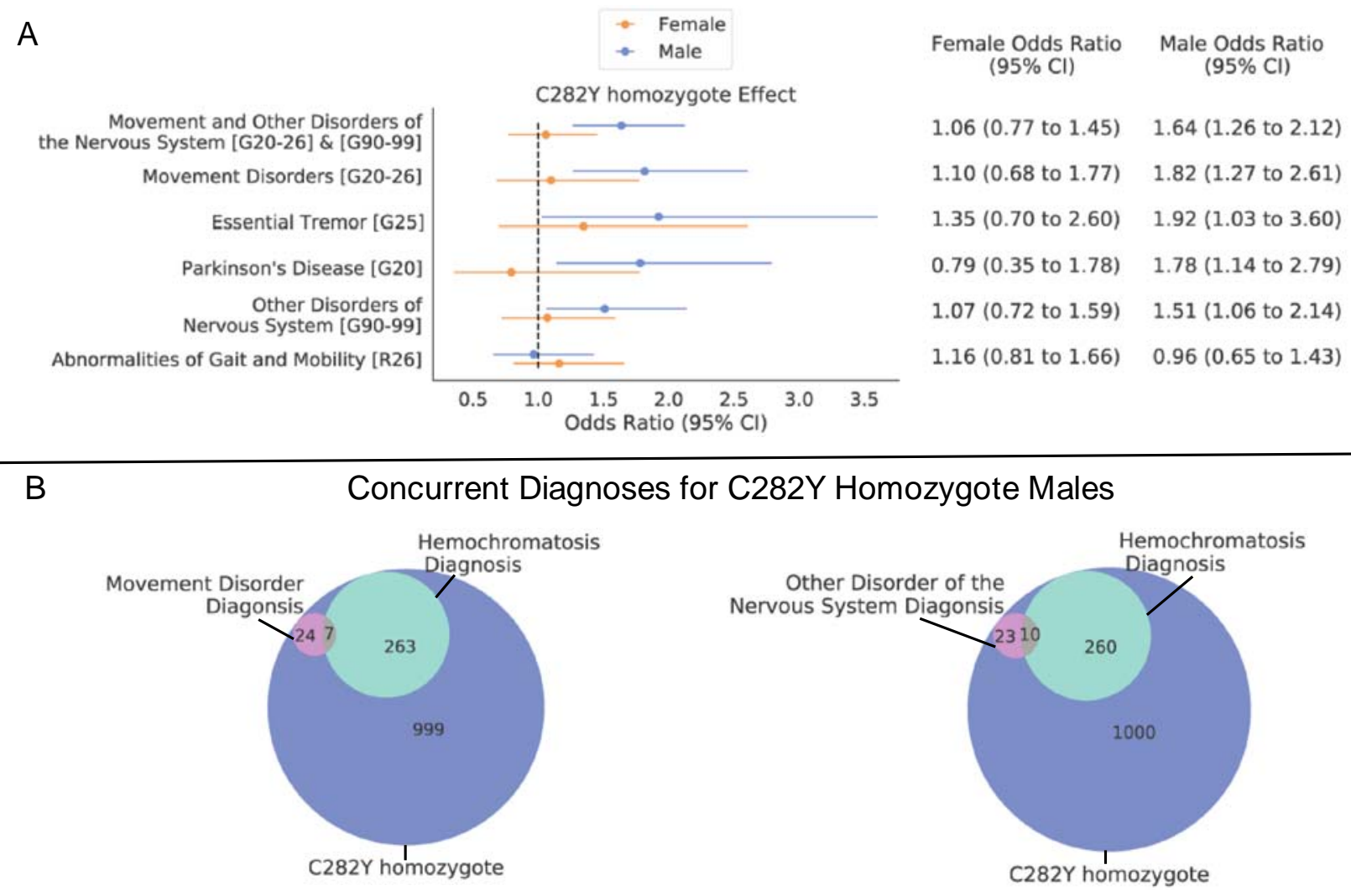

Figure 2 A. sex-stratified effect of C282Y homozygosity for neurological disorders (y axis), values in square brackets indicate ICD10 codes. Dotted vertical line indicates an odds ratio of 1 i.e., null effect. B. Venn diagrams indicating diagnosis overlap for C282Y homozygote males of hemochromatosis and i) movement disorders or ii) other disorders of the nervous system.

\section{Discussion}

We found the most prominent genetic risk factor for HH, p.C282Y homozygosity, was associated with substantially lower $\mathrm{T} 2$ intensities in brain regions related to motor control consistent with iron deposition in these regions. Furthermore, p.C282Y homozygosity in males was associated with increased risk for movement-related disorders and other disorders of the nervous system, but not gait disorders. These results are consistent with both previous case reports of movement disorders in $\mathrm{HH}$ individuals ${ }^{10,11}$, as well as a higher disease burden for p.C282Y homozygote males vs. females ${ }^{2,3}$. Moreover, we found that most p.C282Y homozygote males did not have a concurrent hemochromatosis diagnosis when diagnosed with either i) a 
movement disorder or ii) other disorders of the nervous system. This is of importance given the difference in treatment for $\mathrm{HH}$ and movement disorders.

These results are consistent with a class of disorders termed 'Neurodegeneration with Brain Iron Accumulation' (NBIA) in which rare genetic mutations lead to iron deposition in the basal ganglia ${ }^{21}$. This iron deposition is believed to lead to oxidative damage of these brain regions impairing their function and resulting in movement deficits. Previous conflicting results regarding neurological manifestations of p.C282Y homozygosity ${ }^{5,6,7,8,9}$ have meant that hemochromatosis has traditionally not been included as a cause of NBIA. These conflicting results are probably due to small sample sizes, no stratification based on sex, and biased subject ascertainment. We believe that our study addresses these issues by conducting disease associations in a sample 500 times larger than the previously listed studies, performing sexstratified analysis, and selecting individuals on genotype, not disease status. Furthermore, our neuroimaging results provides strong support that p.C282Y homozygosity imparts a large, selective effect on the brain's motor circuits. The results presented here suggest revisiting p.C282Y homozygosity as a form of NBIA, albeit with reduced penetrance.

The globus pallidus is a region that appears to show large amounts of iron deposition in other NBIA disorders ${ }^{21,22}$, with lower T2 intensities except in juvenile forms ('eye of the tiger'). Additionally, the previous study investigating the p.C282Y homozygosity effect on $\mathrm{T} 2{ }^{*}$ intensities in the same sample as our study found a small to moderate effect in the pallidum ${ }^{14}$. However, our analysis did not reveal differences in T2 intensities in the globus pallidus(Figure 1). The lack of association in our analysis could be due to i) a genuine lack of iron deposition in the pallidum when compared other NBIA disorders or ii) a result of biological processes having opposing effects on T2 intensity (e.g. iron deposition decreasing intensities and gliosis increasing 
intensities) averaging out. Differing sensitivities of T2-weighted vs $\mathrm{T} 2{ }^{*}$-weighted scans to minerals ${ }^{23}$ likely explain the divergence in results of the pallidum between the previous study ${ }^{14}$ and ours. Further research should be conducted to understand processes occurring in the pallidum of p.C282Y homozygotes and if these truly do differ from other NBIA disorders. Post mortem samples and in-vivo imaging of individuals diagnosed with Parkinson's display iron deposition in the brain regions we identified ${ }^{24}$. The most recent genome-wide association study (GWAS) of Parkinson's disease in males did not identify the variant at position p.C282Y as a risk factor $(\mathrm{p}=0.16)^{25}$. We hypothesize this is likely due to the study employing a GWAS standard additive model of inheritance, in which an additional copy of a risk allele imparts a dose-dependent risk. Consistent with findings from previous literature of $\mathrm{HH}^{2}$, here we tested a recessive model of inheritance and observed a relatively sizeable increased risk for movement-related disorders in general $(\mathrm{OR}=1.82)$ and Parkinson's disease in particular $(\mathrm{OR}=1.78)-$ this is in the $5 \times 10^{-6}$ percentile of effect sizes from the most significant previous GWAS of Parkinson's disease in males ${ }^{26}$. Further work needs to be done to verify the size and confidence of this effect in other ancestry groups and populations, particularly given the nonuniform distribution of p.C282Y across the globe (see supplementary Figure 3).

Additionally, although we observe largest T2 intensity reductions (compatible with iron accumulation) in male p.C282Y homozygotes, we still observe a reduction in females and a nonsignificant increase risk for movement disorders. If, as others have $\operatorname{argued}^{3}$, menstruation expels iron from the body, we may be observing the post-menopausal accumulation of iron that has not had enough time to impart the toxic effects compared to males. Indeed, the average age of the women in our neuroimaging study was 64 years old. Furthermore, estrogen may be playing an antioxidant role that is moderating the damaging effects of iron overload ${ }^{27}$. 
Although our neuroimaging results are consistent with iron accumulation in associated regions of the brain, lower T2 intensities may also indicate calcification. Indeed a recent case study reported an $\mathrm{HH}$ individual who displayed both iron and calcium accumulation for the same brain regions discovered in our analysis ${ }^{28}$. One possible explanation for this observed calcium deposition is that calcium and iron homeostasis are reciprocally connected within these regions. This hypothesis is supported by work demonstrating that iron, as Fe2+ ions, can lead to build of inorganic pyrophosphate with calcium ${ }^{29}$. Additional brain imaging of HH and p.C282Y homozygote individuals, using different imaging modalities, may further elucidate the mineral composition of the abnormalities we have observed.

The convergent evidence we have shown consistent with iron deposition in motor circuits of the brain and enrichment for movement and neurological disorders, in those who are homozygous for p.C282Y suggests considering p.C282Y homozygosity as a risk factor for movement disorders in males. Furthermore, given that early treatment of $\mathrm{HH}$ has been shown to be effective in preventing the negative health manifestations of the disease outside of the nervous system $^{3}$, our findings provide additional support for revisiting the public health implications of early screening of populations in which this variant is particularly prevalent.

Funding: R.L was supported by Kavli Innovative Research Grant under award number 20191624. C.F. was supported by grant R01MH122688 and RF1MH120025 funded by the National Institute for Mental Health (NIMH).

Conflict of Interest: A.M.D. reports that he was a Founder of and holds equity in CorTechs Labs, Inc., and serves on its Scientific Advisory Board. He is a member of the Scientific Advisory Board of Human Longevity, Inc. He receives funding through research grants from GE 
medRxiv preprint doi: https://doi.org/10.1101/2021.08.16.21262117; this version posted August 24, 2021. The copyright holder for this preprint (which was not certified by peer review) is the author/funder, who has granted medRxiv a license to display the preprint in perpetuity.

It is made available under a CC-BY-NC 4.0 International license .

Healthcare to UCSD. The terms of these arrangements have been reviewed by and approved by

UCSD in accordance with its conflict-of-interest policies. No other authors report a conflict of interest.

\section{Bibliography}

1. Adams, P. C. Epidemiology and diagnostic testing for hemochromatosis and iron overload. Int. J. Lab. Hematol. 37, 25-30 (2015).

2. Pilling, L. C. et al. Common conditions associated with hereditary haemochromatosis genetic variants: Cohort study in UK Biobank. BMJ 364, (2019).

3. Powell, L. W., Seckington, R. C. \& Deugnier, Y. Haemochromatosis. Lancet 388, 706716 (2016).

4. Bomford, A. Genetics of haemochromatosis. Lancet 360, 1673-1681 (2002).

5. Dekker, M. C. J. et al. Mutations in the hemochromatosis gene (HFE), Parkinson's disease and parkinsonism. Neurosci. Lett. 348, 117-119 (2003).

6. Guerreiro, R. J. et al. Association of HFE common mutations with Parkinson's disease, Alzheimer's disease and mild cognitive impairment in a Portuguese cohort. BMC Neurol. 6, 1-8 (2006).

7. Aamodt, A. H. et al. Prevalence of haemochromatosis gene mutations in Parkinson's disease. J. Neurol. Neurosurg. Psychiatry 78, 315-317 (2007).

8. Akbas, N. et al. Screening for mutations of the HFE gene in Parkinson's disease patients with hyperechogenicity of the substantia nigra. Neurosci. Lett. 407, 16-19 (2006).

9. Buchanan, D. D., Silburn, P. A., Chalk, J. B., Le Couteur, D. G. \& Mellick, G. D. The Cys282Tyr polymorphism in the HFE gene in Australian Parkinson's disease patients. Neurosci. Lett. 327, 91-94 (2002).

10. Kumar, N., Rizek, P., Sadikovic, B., Adams, P. C. \& Jog, M. Movement disorders associated with hemochromatosis. Can. J. Neurol. Sci. 43, 801-808 (2016).

11. Nielsen, J. E., Jensen, L. N. \& Krabbe, K. Hereditary haemochromatosis: A case of iron accumulation in the basal ganglia associated with a parkinsonian syndrome. J. Neurol. Neurosurg. Psychiatry 59, 318-321 (1995).

12. Berg, D. et al. The basal ganglia in haemochromatosis. Neuroradiology 42, 9-13 (2000).

13. Burn, D. Oxford Textbook of Movement Disorders. (Oxford University Press, 2013). doi:10.1093/med/9780199609536.001.0001

14. Atkins, J. L. et al. Hemochromatosis mutations, brain iron imaging, and dementia in the UK Biobank cohort. J. Alzheimer's Dis. 79, 1203-1211 (2021).

15. Burn, D. Oxford Textbook of Movement Disorders. (Oxford University Press, 2013). doi:10.1093/med/9780199609536.001.0001

16. Herrero, M. T., Barcia, C. \& Navarro, J. M. Functional anatomy of thalamus and basal ganglia. Child's Nerv. Syst. 18, 386-404 (2002).

17. Gandon, Y. et al. Non-invasive assessment of hepatic iron stores by MRI. Lancet 363, 357-362 (2004).

18. McComb, R. D. Neuropathology: A Volume in the Foundations of Diagnostic Pathology Series. Am. J. Surg. Pathol. 30, (2006). 
medRxiv preprint doi: https://doi.org/10.1101/2021.08.16.21262117; this version posted August 24, 2021. The copyright holder for this preprint (which was not certified by peer review) is the author/funder, who has granted medRxiv a license to display the preprint in perpetuity.

It is made available under a CC-BY-NC 4.0 International license .

19. Takakusaki, K. Functional Neuroanatomy for Posture and Gait Control. J. Mov. Disord. 10, 1-17 (2017).

20. Poewe, W. et al. Parkinson disease. Nat. Rev. Dis. Prim. 3, 1-21 (2017).

21. Hayflick, S. J., Kurian, M. A. \& Hogarth, P. Chapter 19 - Neurodegeneration with brain iron accumulation. in Neurogenetics, Part I (eds. Geschwind, D. H., Paulson, H. L. \& Klein, C. B. T.-H. of C. N.) 147, 293-305 (Elsevier, 2018).

22. Kruer, M. C. et al. Neuroimaging features of neurodegeneration with brain iron accumulation. Am. J. Neuroradiol. 33, 407-414 (2012).

23. Labranche, R. et al. Liver iron quantification with MR imaging: A primer for radiologists. Radiographics 38, 392-412 (2018).

24. Wang, J. Y. et al. Meta-analysis of brain iron levels of Parkinson's disease patients determined by postmortem and MRI measurements. Sci. Rep. 6, 1-13 (2016).

25. Blauwendraat, C. et al. Investigation of Autosomal Genetic Sex Differences in Parkinson's disease. medRxiv 2021.02.09.21250262 (2021). doi:10.1101/2021.02.09.21250262

26. Blauwendraat, C. et al. Investigation of Autosomal Genetic Sex Differences in Parkinson's disease. medRxiv 2021.02.09.21250262 (2021). doi:10.1101/2021.02.09.21250262

27. Zárate, S., Stevnsner, T. \& Gredilla, R. Role of estrogen and other sex hormones in brain aging. Neuroprotection and DNA repair. Front. Aging Neurosci. 9, 1-22 (2017).

28. Scarlini, S. et al. Idiopathic brain calcification in a patient with hereditary hemochromatosis. BMC Neurol. 20, 1-5 (2020).

29. McCarty, D. J. \& Pepe, P. F. Erythrocyte neutral inorganic pyrophosphatase in pseudogout. J. Lab. Clin. Med. 79, 277-284 (1972).

30. Bycroft, C. et al. The UK Biobank resource with deep phenotyping and genomic data. Nature 562, 203-209 (2018).

31. Jovicich, J. et al. Reliability in multi-site structural MRI studies: Effects of gradient nonlinearity correction on phantom and human data. Neuroimage 30, 436-443 (2006).

32. Wald, L., Schmitt, F. \& Dale, A. Systematic spatial distortion in MRI due to gradient nonlinearities. Neuroimage 13, 50 (2001).

33. Wells, W. Multi-modal volume registration by maximization of mutual information. Med. Image Anal. 1, 35-51 (1996).

34. Hagler, D. J. et al. Image processing and analysis methods for the Adolescent Brain Cognitive Development Study. Neuroimage 202, (2019).

35. Fischl, B. et al. Whole brain segmentation: Automated labeling of neuroanatomical structures in the human brain. Neuron 33, 341-355 (2002).

36. Pauli, W. M., Nili, A. N. \& Michael Tyszka, J. Data Descriptor: A high-resolution probabilistic in vivo atlas of human subcortical brain nuclei. Sci. Data 5, 1-13 (2018).

37. Najdenovska, E. et al. In-vivo probabilistic atlas of human thalamic nuclei based on diffusion-weighted magnetic resonance imaging. Sci. Data 5, 1-11 (2018).

38. Rosenbaum, P. R. \& Rubin, D. B. Constructing a control group using multivariate matched sampling methods that incorporate the propensity score. Am. Stat. 39, 33-38 (1985).

39. Benmiroglio. pymatch. Available at: https://github.com/benmiroglio/pymatch. 